\title{
The Reliability and Validity of Felder- Silverman Index of Learning Styles in Mandarin Version
}

\author{
Jingyun Wang *, Takahiko Mendori ${ }^{\dagger}$
}

\begin{abstract}
This paper offers a contribution to the validation work on the ILS instrument based on the author's study of the relationship between learning styles and learning performances in a language learning support system. An analysis on 198 valid questionnaires, collected from Chinese-native undergraduate students in responds to a Mandarin translation of Felder- Silverman Index of Learning Styles, are discussed. The discussion includes internal reliability, inter-scale correlation and construct validity. In the terms of construct validity, the trends of learning style preferences with respect to gender and the field of study are investigated.
\end{abstract}

Keywords: Felder-Silverman learning style, index of learning styles, internal consistency, construct validity.

\section{Introduction}

Learning styles has been integrated as a system parameter for the personalization of learning scenarios in numerous adaptive systems [1] [2] [3] [4]. Although more than 70 learning style models are described in the literature [5] and different models are used by various adaptive systems to classify learners into supposedly distinct groups or to assign learners graded scores on single or multiple dimensions [6]. In this paper we discuss the widely adopted Felder-Silverman learning style model (FSLSM) [7] [8] which carefully formulates the individual differences in four dimensions.

FSLSM was firstly presented for Engineering Education by Felder and Silverman in 1988 and revised by Felder in 2002. This model was also extended to foreign and second language education by Felder and Henriques in 1995. As shown in Figure 1, FSLSM defines four dimensions of learning style: Active/Reflective, Sensing/Intuiting, Visual/Verbal, and Sequential/Global. The first dimension is about information processing: learners of active scale tend to understand the knowledge through active trial, discussion or by explaining it to others while learners of reflective scale tend to observe reflectively. The second dimension involves information perception: learners of sensing scale prefer to perceive data by the senses while learners of intuiting scale prefer by accessing memories or insights. The third dimension refers to information reception: visual

\footnotetext{
* Kyushu university, Fukuoka, Japan

$\dagger$ Kochi University of Technology, Kochi, Japan
} 
learners prefer that information is presented by diagrams, flow charts, pictures or films rather than in written words, which is preferred by verbal learners. The last dimension involves information understanding: sequential learners gain understanding in logically linear steps while global learners need the big picture of a subject before mastering details. It is worthy to notice that "these four dimensions have not been shown to be fully independent" ([8], p.27).

\begin{tabular}{|c|c|c|c|}
\hline & rocessing & & rception \\
\hline Active & Reflective & Sensing & Intuitive \\
\hline $\begin{array}{l}\text { discussing/ } \\
\text { applying/ } \\
\text { explaining to } \\
\text { others }\end{array}$ & $\begin{array}{l}\text { think about } \\
\text { it quietly } \\
\text { first }\end{array}$ & $\begin{array}{l}\text { be patient with details } \\
\text { and good at } \\
\text { memorizing facts }\end{array}$ & $\begin{array}{l}\text { prefer discovering possibilities } \\
\text { and relationships, } \\
\text { grasping new concepts } \\
\text { /abstractions }\end{array}$ \\
\hline group work & $\begin{array}{l}\text { working } \\
\text { alone }\end{array}$ & $\begin{array}{l}\text { solving problems by } \\
\text { well-established } \\
\text { methods or practice }\end{array}$ & $\begin{array}{l}\text { like innovation / } \\
\text { dislike repetition }\end{array}$ \\
\hline & Reception & \multicolumn{2}{|c|}{ Understanding } \\
\hline Visual & Verbal & Sequential & Global \\
\hline \multirow{2}{*}{$\begin{array}{l}\text { pictures, } \\
\text { diagrams, } \\
\text { flow charts, } \\
\text { time lines, films, } \\
\text { and } \\
\text { demonstrations }\end{array}$} & \multirow[t]{2}{*}{$\begin{array}{l}\text { written and } \\
\text { spoken } \\
\text { explanations }\end{array}$} & $\begin{array}{l}\text { absorb information in } \\
\text { small connected } \\
\text { pieces }\end{array}$ & $\begin{array}{l}\text { need the big picture of a } \\
\text { subject before mastering } \\
\text { details }\end{array}$ \\
\hline & & $\begin{array}{l}\text { gain understanding in } \\
\text { logically linear steps }\end{array}$ & $\begin{array}{l}\text { how the material being } \\
\text { presented relates to } \\
\text { The prior knowledge and } \\
\text { experience }\end{array}$ \\
\hline
\end{tabular}

Figure 1: The four dimensions defined by FSLSM

The Index of Learning Styles (ILS) is an instrument designed based on FSLSM to assess the cognitive styles of the learner and its current version was suggested to be reliable, valid and suitable for capturing learners' behavioral tendencies [9]. This instrument were adopted by many adaptive systems to identify learning styles of learners. For instance, Hwang et al. [4] proposes a personalized game-based learning approach incorporating the sequential/global dimension of FSLSM. The programming tutoring system "Protus" [10] also forms clusters of learners based on their responses towards ILS and then mines the behavioral patterns for each cluster with AprioriAll algorithm [11] to create a recommendation list for individuals of each cluster according to the system's ratings of mined frequent sequences.

Although reference [9] elaborately describes the reliability and validity analysis of Englishlanguage version ILS [12] which was designed for native English speaker, few literature describes the analysis of the translation versions of ILS except for the Portuguese version used in [13] [14]. It is meaningful to investigate the reliability and validity of Felder-Soloman ILS in other translation versions. Therefore, this paper offers a contribution to the validation work on the ILS instrument based on the data collected from Chinese-native undergraduate students in responds to a Mandarin version of ILS. The internal reliability, inter-scale correlation and construct validity are all considered. 


\section{Participants}

In our previous work, a series of experiments were conducted to study the learning performance of undergraduate students who studied Japanese language with the support of a personalized elearning system [15]. 198 undergraduate students (including 60 Engineering students and 138 Language students) from 4 Chinese universities participated in those experiments. Their learning style distribution data was collected for the investigation of the relationship between learning styles and learning performances. The measuring tool adopted was a questionnaire written in Mandarin, translated from the ILS of 44 questions [12]. All the participants (84 male and 114 female) were voluntarily to fill in this questionnaire.

\section{Results and discussion}

The learning style profiles based on the responses to ILS questionnaire are shown in Figure 2. According to Felder and spurlin [9], each learning style dimension has associated with 11 forcechoice items, with each option ( $\mathrm{a}$ or b) corresponding to one or the other category of the dimension (such as active or reflective). Given visual/verbal dimension as an example, based on the responses to its related 11 items, participant would be identified as having strong, moderate or mild preference for visual or verbal. Learner with strong or moderate preference for one category normally is stably exhibiting consistent learning behavior. Conversely, learner with mild preferences would be expected to shift their preference in learning activities readily.

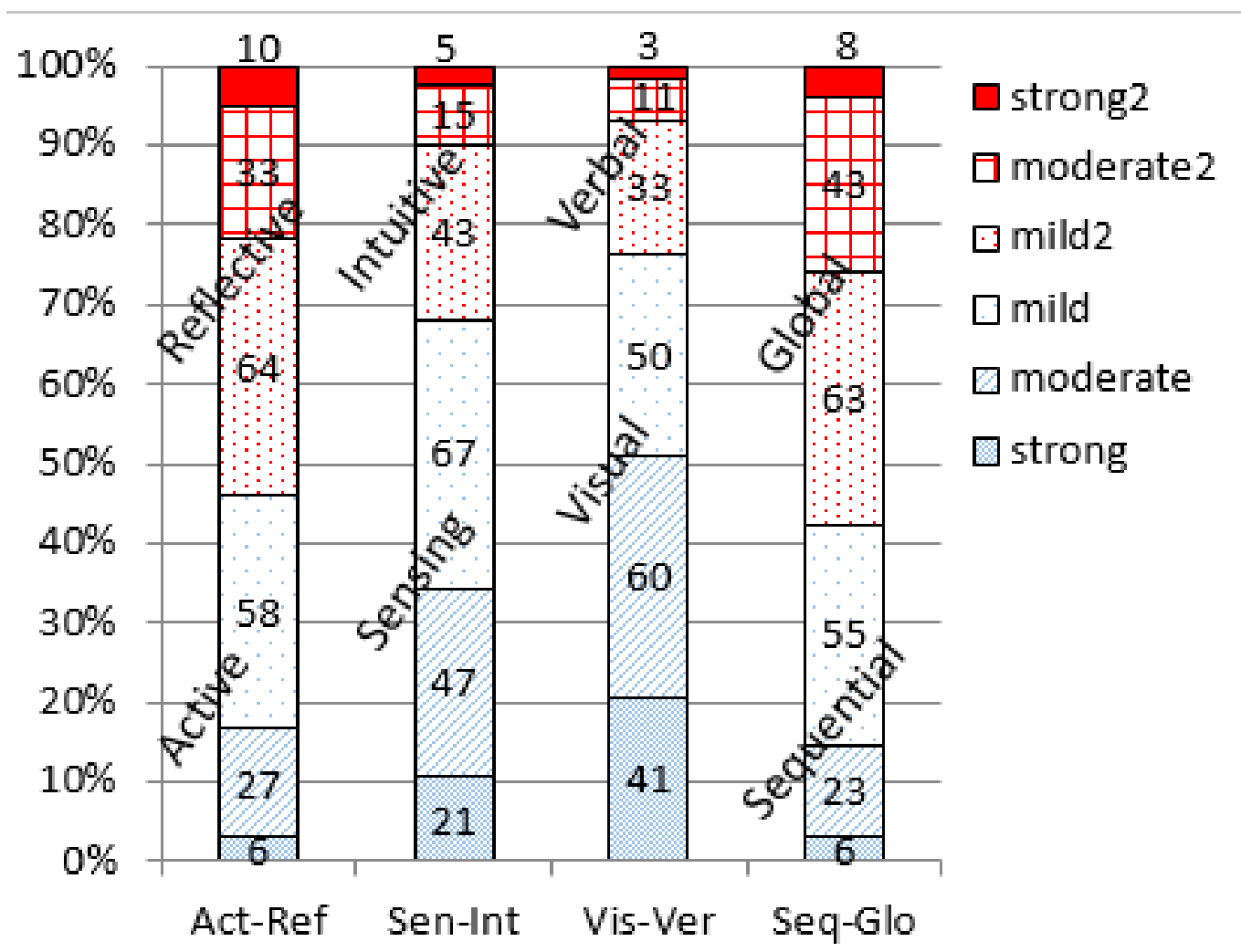

Figure 1: Reported learning style preferences 
In statistical analysis, the responses were normally scored for the Active, Sensing, Visual and Sequential scales by assigning a value of 1 to (a) items, and 0 to (b) items. For example, as shown in Figure 2, in the Active/Reflective dimension, $15.7 \%$ of participants submitted between 8 and 11 "a" responses indicating a moderate or strong preference for active learning; $56.6 \%$ of participants submitted 4-7 "a" responses indicating a mild preference in this dimension; $21.7 \%$ of participants submitted 0-3 "a" responses indicating a moderate or strong preference for Reflective learning.

Except for the Visual/ Verbal Dimension, more than half of participants were found with mild preferences in other dimensions $(56.6 \%$ for Active/Reflective, 55.6\% for Sensing/Intuiting, $59.6 \%$ for Sequential/Global). Meanwhile, large percentage of participants (51\%) are identified as stable visual learners, who strongly prefer that information be presented visually while only $7 \%$ of them are stable verbal learners who strongly prefer spoken or written explanations to visual presentations and $41.9 \%$ of them with mild preference for visual or verbal are fairly well balanced in the dimension of Visual /Verbal. These findings are generally consistent with those reported in past studies [9]. In additional, for Sensing/Intuiting dimension, $34.4 \%$ of student are stable (moderate or strong) Sensing learners while $10.1 \%$ of student are stable Intuiting learners; for Sequential/Global dimension, $25.8 \%$ of student are stable Sequential learners while $14.6 \%$ of student are stable Global learners.

\subsection{Internal Consistency Reliability}

Cronbach's alpha is commonly used to measure the internal consistency of scales of a questionnaire. The higher the score, the more reliable the generated scale is. Tuckman [16] suggest that alpha test reliability should be above 0.75 for achievement tests and above 0.5 for attitude tests. Table 1 shows the analysis results of internal reliability performed on the (a) items in each scale for all 198 valid ILS questionnaires. The internal reliability of the scales was found to range from 0.51 to 0.65 . As in [17] [18] [19], the weakest reliability was found in Sequential/Global scale. The resulting coefficients meet acceptable limits as suggested in [16].

Table 1: Internal consistency reliability for the ILS

\begin{tabular}{cccccc}
\hline Dimension & Case & Items & Scale Mean & Scale STD & Cronbach's alpha \\
\hline \hline Act-Ref & 198 & 11 & 5.2424 & 2.2602 & 0.514 \\
Sen-Int & 198 & 11 & 6.5404 & 2.2790 & 0.625 \\
Vis-Ver & 198 & 11 & 7.2525 & 2.3943 & 0.644 \\
Seq-Glo & 198 & 11 & 5.1263 & 2.2302 & 0.509 \\
\hline
\end{tabular}

The Direct inter-scale correlation was also considered by calculated the Pearson's correlation coefficients computed between scores on the ILS scales. As shown in Table 2, most of scales had negligible inter-scale correlation except for a moderate correlation $(\mathrm{r}=0.370)$ observed between the Sensing and Sequential scores. This finding is also consistent with the results described in [17] [18] [19], which found the overlap between Sensing and Sequential scales as well as the inter-scale correlation between them. As stated in [9], this finding is not unexpected and in fact supports the construct validity of ILS which is intended to help instructors formulate a balanced 
leaning style. For instances, discovering some methods that can not only meet the need of intuitive learners but also benefit global learners, may ease the workload of instructors.

Table 2: Correlations between scale scores of the ILS

\begin{tabular}{cccccc}
\hline & & Act-Ref & Sen-Int & Vis-Ver & Seq-Glo \\
\hline \hline \multirow{2}{*}{ Act-Ref } & Pearson Correlation & 1 & & & \\
& Sig. (2-tailed) & & & & \\
Sen-Int & Pearson Correlation & $0.146^{*}$ & & & \\
& Sig. (2-tailed) & 0.040 & 1 & & \\
& Pearson Correlation & $0.191^{* *}$ & $0.177^{*}$ & & \\
Vis-Ver & Sig. (2-tailed) & 0.007 & 0.013 & & \\
& Pearson Correlation & 0.064 & $0.370^{* *}$ & -.071 & 1 \\
Seq-Glo & Sig. (2-tailed) & 0.367 & 0.000 & 0.323 & \\
& & $*$. Correlation is significant at the 0.05 level (2-tailed). & \\
& & $* *$ Correlation is significant at the 0.01 level (2-tailed).
\end{tabular}

\subsection{Construct Validity}

The responses to ILS questionnaire in this study were also used to investigate trends with respect to gender and the field of study. Reference [20] reports that there are no significant interaction effects among gender and the field on all scales. However, among the engineering students in this study only 6 of them are female. The analysis results on all the collected data may not represent the general situation. Therefore, only the analysis of the gender effect on the data of participants who major in Language are conducted. Table 3 suggests that learning styles of students in Language department did not have significantly differences in terms of gender. This supports the convergent construct validity of the ILS, as female and male students in Language department share many characteristics hypothesized by the model. (For engineering students, significant mean differences between genders on all scales except for active-reflective were found in [20].)

Table 3: Means, Standard Deviations and ANOVA Results for Comparisons between Female and male Students from Language department in ILS Scores

\begin{tabular}{|c|c|c|c|c|c|c|c|c|c|}
\hline \multirow[t]{2}{*}{ Gender } & \multirow[t]{2}{*}{$\mathrm{N}$} & \multicolumn{2}{|c|}{$\begin{array}{l}\text { Active } \\
\text { Score }\end{array}$} & \multicolumn{2}{|c|}{ Sensing Score } & \multicolumn{2}{|c|}{ Visual Score } & \multicolumn{2}{|c|}{$\begin{array}{l}\text { Seq. } \\
\text { Score }\end{array}$} \\
\hline & & Mean & STD & Mean & STD & Mean & STD & Mean & STD \\
\hline Female & 108 & 5.01 & 2.13 & 6.73 & 2.12 & 7.06 & 2.31 & 5.11 & 2.30 \\
\hline Male & 30 & 5.11 & 2.77 & 6.36 & 2.45 & 7.18 & 2.52 & 5.21 & 2.18 \\
\hline \multicolumn{2}{|c|}{$A N O V A$} & \multicolumn{2}{|c|}{$p=0.848$} & \multicolumn{2}{|c|}{$p=0.436$} & \multicolumn{2}{|c|}{$p=0.811$} & \multicolumn{2}{|c|}{$p=0.837$} \\
\hline
\end{tabular}

There is also support for discriminant validity of the ILS, with significant differences in scores for undergraduate from different fields. In this study, the author compared the learning styles of students from engineering and Language department, as shown in Table 4. There were statistically significant differences at 0.05 level between 60 engineering students and 138 language students in the mean scores on Active/Reflective and Visual/Verbal scales, with engineering students predominantly more Reflective and Visual than Language students. 
Table 4: Means, Standard Deviations and ANOVA Results for Comparisons between Engineering and Language students in ILS Scores

\begin{tabular}{|c|c|c|c|c|c|c|c|c|c|}
\hline \multirow[t]{2}{*}{ Field } & \multirow[t]{2}{*}{$\mathrm{N}$} & \multicolumn{2}{|c|}{$\begin{array}{l}\text { Active } \\
\text { Score }\end{array}$} & \multicolumn{2}{|c|}{ Sensing Score } & \multicolumn{2}{|c|}{ Visual Score } & \multicolumn{2}{|c|}{$\begin{array}{l}\text { Seq. } \\
\text { Score }\end{array}$} \\
\hline & & Mean & STD & Mean & STD & Mean & STD & Mean & STD \\
\hline $\begin{array}{l}\text { Engineer- } \\
\text { ing }\end{array}$ & 60 & 5.08 & 2.08 & 6.56 & 2.37 & 7.54 & 2.40 & 4.82 & 2.13 \\
\hline $\begin{array}{l}\text { Language } \\
\qquad \boldsymbol{A N O \boldsymbol { A }} \boldsymbol{A}\end{array}$ & 138 & \multicolumn{2}{|c|}{$p=0.018^{*}$} & $p=0.540$ & $\begin{array}{l}2.20 \\
540\end{array}$ & $\begin{array}{l}7.09 \\
p=0\end{array}$ & $p=0.023^{*}$ & \multicolumn{2}{|c|}{$p=0.329$} \\
\hline
\end{tabular}

\section{Conclusion and recommendations}

In this study, the reliability estimate of the scores for the four scales of the Mandarin version ILS based on Cronbach alphas ranged from 0.51 to 0.65 . This suggests the Mandarin version of ILS satisfies the criterion of acceptability. In terms of inter-scale correlation, there was moderate correlation between Sensing/Intuitive and Sequential/Global dimensions, which was also observed in the other studies [17] [18] [19].

The data was used to explore possible gender differences in learning style preferences between male and female language students. The analysis results on learning styles of language students indicate that there are no significant mean differences between genders on all scales. However, since there are few studies addressing the effect of gender on learning styles data based on ILS, the practical implication and its generality remain to be investigated.

The data set was also used to compare the reported learning styles of students in Engineering with those in Language. The analysis revealed that the engineering students are significantly more Reflective and Visual than Language students. This suggests that instructors of engineering students should try to encourage their students to participate more in active or verbal tasks. A balance of instructional methods is the best way to make learners achieve effective learning. Researchers [8] [21] [22] argued that learners will inevitably need to deal with problems and challenges that require the use of their less preferred mode. Therefore, the learners should regularly be given practice in the use of less preferred modes, even that they might have stress and frustration.

In summary, ILS was an appropriate and statistically acceptable instrument for characterizing learning style. This questionnaires for accessing cognitive style focus on the ratings of general descriptions about learning scenario. It is worthy to notice that cognitive style (i.e., tendency to use visual or verbal modes of knowledge representation and thinking) is distinguished from cognitive ability (i.e., proficiency in creating, holding, and manipulating spatial representations) and learning preference (i.e., preference for receiving instruction involving pictures or words when learners interact with a particular learning situation) [23]. On the other hands, despite the large size of literature on learning styles, correlation between the learning styles and academic performance is was scarcely discussed and hardly supported [24]. Our previous study [15] also revealed that the learning styles identified by ILS was only related to learning perception (i.e., mental load or technique acceptance) and not related to academic performances while studying with a learning support system. The original intension of ILS is to provide both the learners and the instructor with an insight into how they approach the learning/teaching process. As advocated in [19], further works on analysis of responses to ILS can encourage learners/instructors to expand the range 
of learning/teaching strategies.

\section{Acknowledgement}

Our sincere thanks go to Prof. Gwo-Jen Hwang for providing the Taiwanese version of ILS as our references.

\section{References}

[1] S. W. Hsieh, Y. R. Jang, G. J. Hwang, \& N. S. Chen, "Effects of Teaching and Learning Styles on Students' Reflection Levels for Ubiquitous learning," Computers \& Education, 2011, pp. 1194-1201.

[2] T. C. Yang, G. J. Hwang, \& J. H. Yang, Stephen, "Development of An Adaptive Learning System with Multiple Perspectives based on Students' Learning Styles and Cognitive Styles," Educational Technology \& Society, 2013, pp. 185-200.

[3] G. J. Hwang, H. Y. Sung, C. M. Hung, \& I. Huang, "A Learning Style Perspective to Investigate the Necessity of Developing Adaptive Learning Systems," Educational Technology \& Society, 2013, pp. 188-197.

[4] G. J. Hwang, H. Y. Sung, C. M. Hung, I., Huang,\& C. C. Tsai, "Development of A Personalized Educational Computer Game based on Students' Learning Styles," Educational Technology Research \& Development, 2012, pp. 623-638.

[5] F. Coffield, D. Moseley, E. Hall, and K. Ecclestone, "Learning Styles and Pedagogy in Post16 Learning: A systematic and Critical Review," London: Learning and Skills Research Centre, 2004.

[6] H. Pashler, M. McDaniel, D. Rohrer, R. Bjork, "Learning Styles: Concepts and Evidence," Psychological Science in the Public Interest, 2009, pp. 105-119.

[7] R. M. Felder, and L. K. Silverman, "Learning Styles and Teaching Styles in Engineering Education," Engineering Education, 1988, pp. 674-681.

[8] R. M. Felder and E.R. Henriques, "Learning and Teaching Styles in Foreign and Second Language Education," Foreign Language Annals, 1995, pp. 21-31.

[9] R.M. Felder and J.E. Spurlin, "Applications, Reliability, and Validity of the Index of Learning Styles”, Intl. Journal of Engineering Education, 2005, pp. 103-112.

[10] A.Klašnja-Milićević, B.Vesin, M.Ivanović, \&, Z. Budimac, "E-Learning Personalization based on Hybrid Recommendation Strategy and Learning Style Identification," Computers \& Education, 2011, pp. 885-899.

[11] W. Tong, \& H. Pi-Lian, "Web Log Mining by an Improved Aprioriall Algorithm. In: Proceeding of World Academy of Science, Engineering, and Technology," 2005, pp. 97-100. 
[12] B. A. Soloman, and R. M. Felder, "Index of Learning Styles Questionnaire," 2001; http://www.engr.ncsu.edu/learningstyles/ilsweb.html retrieved [March 1, 2013].

[13] W. M. G. Lopes, "ILS - Inventário de Estilos de Aprendizagem de Felder- de Soloman: Investigação de Sua Validade em Estudantes Universitários de Belo Horizonte", master dissension: University Federal de Santa Catarina, Brazil, 2002.

[14] N.P. Kuri, and O.M.S Truzzi, "Learning Styles of Freshmen Engineering Students", Proceedings of the 2002 International Conference on Engineering Education (ICEE), 2002, Arlington.

[15] J.Y. Wang, \& T. Mendori and J. Xiong, "A Language Learning Support System using Course-centered Ontology and Its Evaluation,” Computer \& Education, 2014, pp. 278-293.

[16] B.W. Tuckman, Conducting Educational Research, 5th edition, Belmont, CA: Wadsworth Group, 1999.

[17] G. A. Livesay, K. C. Dee, E. A. Nauman and L. S. Hites, Jr., "Engineering Student Learning Styles: a Statistical Analysis Using Felder's Index of Learning Styles", 2002 conference of the American society for engineering education, June 2002, Montreal, Quebec.

[19] N. Van Zwanenberg, L J. Wilkinson, \& A. Anderson, "Felder and Silverman's Index of Learning Styles and Honey and Mumford's Learning Styles Questionnaire: How do They Compare and Do They Predict Academic Performance?” Educational Psychology, 2000, pp. 365-381.

[20] M.S. Zywno, “A Contribution to Validation of Score Meaning for Felder Soloman's Index of Learning Styles", Proceedings of the 2003 ASEE Annual Conference, 2003, ASEE.

[21] P. Friedman, and R. Alley, "Learning/Teaching Styles: Applying the Principles," Theory into Practice, 1984, pp. 77-81.

[22] V. Cox, "Some Implications of Cognitive Science, Cognitive Psychology, and Human Information Processing for Engineering Education of the Future: Problem Solving, Cognition and Metacognition," 1988 Annual Conference Proceedings of American Society for Engineering Education, 1988, Portland.

[23] T. A. Litzinger, S. H. Lee, J. C. Wise and, R. M. Felder, "A Study of the Reliability and Validity of the Felder-Soloman Index of Learning Styles", Proceedings of the 2005 American Society for Engineering Education Annual Conference \& Exposition, 2005.

[24] R. E. Mayer, and L. Massa, "Three Facets of Visual and Verbal Learners: Cognitive Ability, Cognitive Style, and Learning Preference," Journal of Educational Psychology, 2003, pp. 833-841.

[25] H. Pashler, M. McDaniel, D. Rohrer, R. Bjork, "Learning styles: Concepts and Evidence," Psychological Science in the Public Interest, 2009, pp. 105-119. 